\title{
Factors Associated with Cesarean Section among Primiparous Women in Georgia: A Registry-based Study
}

\author{
Ingvild Hersoug Nedberg ${ }^{1 *},(\mathbb{D})$, Charlotta Rylander ${ }^{1,(\mathbb{D})}$, Finn Egil Skjeldestad ${ }^{1,(\mathbb{D})}$, Ellen Blix ${ }^{2,}$ (D), \\ Tamar Ugulava ${ }^{3}$, Erik Eik Anda ${ }^{1,(D)}$ \\ ${ }^{1}$ Department of Community Medicine, Faculty of Health Sciences, UiT The Arctic University of Norway, Tromsø, Norway \\ ${ }^{2}$ Department of Nursing and Health Promotion, Faculty of Health Sciences, OsloMet - Oslo Metropolitan University, Oslo, Norway \\ ${ }^{3}$ United Nations Children's Fund (UNICEF), Tbilisi, Georgia
}

\section{ARTICLE INFO}

Article History

Received 21 January 2020

Accepted 11 July 2020

Keywords

Cesarean section

maternal health

maternal health services

registries

primiparity

gestational age

Georgia (Republic)

\begin{abstract}
Cesarean section rates remain high in Georgia. As a cesarean section in the first pregnancy generally lead to a cesarean section in subsequent pregnancies, primiparous women should be targeted for prevention strategies. The aim of the study was to assess factors associated with cesarean section among primiparous women. The study comprised 17,065 primiparous women with singleton, cephalic deliveries at 37-43 weeks of gestation registered in the Georgian Birth Registry in 2017. The main outcome was cesarean section. Descriptive statistics and logistic regression analysis were used to identify factors associated with cesarean section. The proportion of cesarean section was $37.1 \%$ with regional variations from $14.2 \%$ to $57.4 \%$. Increased maternal age, obesity and having a baby weighing $\geq 4000$ g were all associated with higher odds of cesarean section. Of serious concern for newborn wellbeing is the high proportion of cesarean section at 37-38 weeks of gestation. Further research should focus on organizational and economical aspects of maternity care to uncover the underlying causes of the high cesarean section rate in Georgia.
\end{abstract}

(C) 2020 The Authors. Published by Atlantis Press International B.V. This is an open access article distributed under the CC BY-NC 4.0 license (http://creativecommons.org/licenses/by-nc/4.0/).

\section{INTRODUCTION}

The proportion of Cesarean Section (CS) is increasing worldwide, despite mounting evidence of associated increased costs and negative impact on maternal and neonatal morbidity [1]. The proportion of CS performed in Georgia has escalated from an estimated $9 \%$ in 2000 [2] to $43.5 \%$ in 2016 [3]. Georgian health authorities have set new goals for maternal and newborn health with an aim to reduce the overall proportion of CS to $31 \%$ by 2020 and $27 \%$ by 2030. The ministry of health has imposed restrictions, or a maximum percentage of CS each of the 102 maternity wards can perform, based on individual assessments. Economic sanctions are used to ensure the facilities meet the aims [4].

Studies from low- and middle-income countries have found associations between high proportions of CS and increased maternal age, higher education, and residing in urban areas [5,6]. From the provider side, financial incentives, doctor's convenience, and fear of litigation are frequently cited as reasons for increased rates of CS [7-9]. Conversely, women under the care of midwives have lower rates of interventions during childbirth than those under the care of physicians [10]. The proportion of CS performed in private sector health care is frequently higher than in the public sector [11].

"Corresponding author. Email: ingvild.h.nedberg@uit.no

Data availability statement: The data that support the findings of this study are available from National Centre for Disease Control \& Public Health in Tbilisi, Georgia, but restrictions apply to the availability of these data, which were used under license for the current study. The data are not publicly available. Data are however available from the authors upon reasonable request and with permission of National Centre for Disease Control \& Public Health in Georgia.
In Georgia, obstetricians are the main maternal care providers, while midwives play a marginal role. Only one university educates midwives and women cannot opt to receive antenatal care from a midwife. Georgia has a privatised health care system, and national guidelines for maternity care do not encourage physicians to perform CS on maternal request. Since CS at first pregnancy may lead to CS in subsequent pregnancies [12], the prevention of a first CS is crucial in reducing the overall proportion of CS. Any comprehensive national strategy with the aim to bring down this proportion must target the appropriate population; thus it is of primary interest to know the demographics, and the pregnancy- and delivery-related conditions among primiparous women in Georgia. Thus, we aimed to assess factors associated with CS among primiparous women with singleton, cephalic deliveries at term in Georgia.

\section{MATERIALS AND METHODS}

The Georgian Birth Registry (GBR) is a national, digital birth registry implemented on January 1, 2016. The GBR contains information from antenatal care visits, hospitalisations during pregnancy, labor, delivery, and the postnatal stay for both mothers and newborn. Registration in the GBR was made mandatory by law on May 1, 2016. Details on the implementation of the GBR and results from its first year have previously been reported [3].

The study sample comprised of all primiparous women $(n=$ 20,936 ) who gave birth at $\geq 22$ weeks of gestation in 2017 and were registered in the GBR. After exclusions, the final study sample 
comprised 17,065 primiparous women with singleton, cephalic deliveries at 37-43 weeks of gestation (Figure 1).

We extracted information from the GBR on all variables included in the study. For maternal age (categorized to: 13-19, 20-24, 25-29, $30-34, \geq 35$ years), women $<20$ years were grouped into one category consisting of 7 years due to low number of women in the 13-14 age group $(n=7)$. We extracted level of education (primary level, secondary, higher education, unknown), maternal geographical region of residence (12 different regions including the capital Tbilisi), onset of labor (spontaneous, induced, or CS) and number of antenatal visits attended ( $\leq 3$ visits, $\geq 4$ visits). In 2017, Georgian universal health care covered four antenatal care visits for low risk women, as recommended by WHO at the time [13]. For the variable weeks of gestation (37-38, 39-40, 41-43), ultrasound in antenatal care is the preferred method to determine gestational age and is widely available nationwide. In case of missing ultrasound ( $18 \%$ of cases), last menstrual period was used. We also extracted delivery mode (spontaneous vaginal, operative vaginal, CS), and birthweight (<2500, 2500-2999, 3000-3499, 3500-3999, $\geq 4000 \mathrm{~g})$. For the variable early-pregnancy Body Mass Index (BMI), we used $\mathrm{BMI}$ at the first antenatal visit before 13 weeks of gestation (categorized to: $\left.<18.5,18.5-24.99,25.00-29.99, \geq 30.00 \mathrm{~kg} / \mathrm{m}^{2}\right)$.

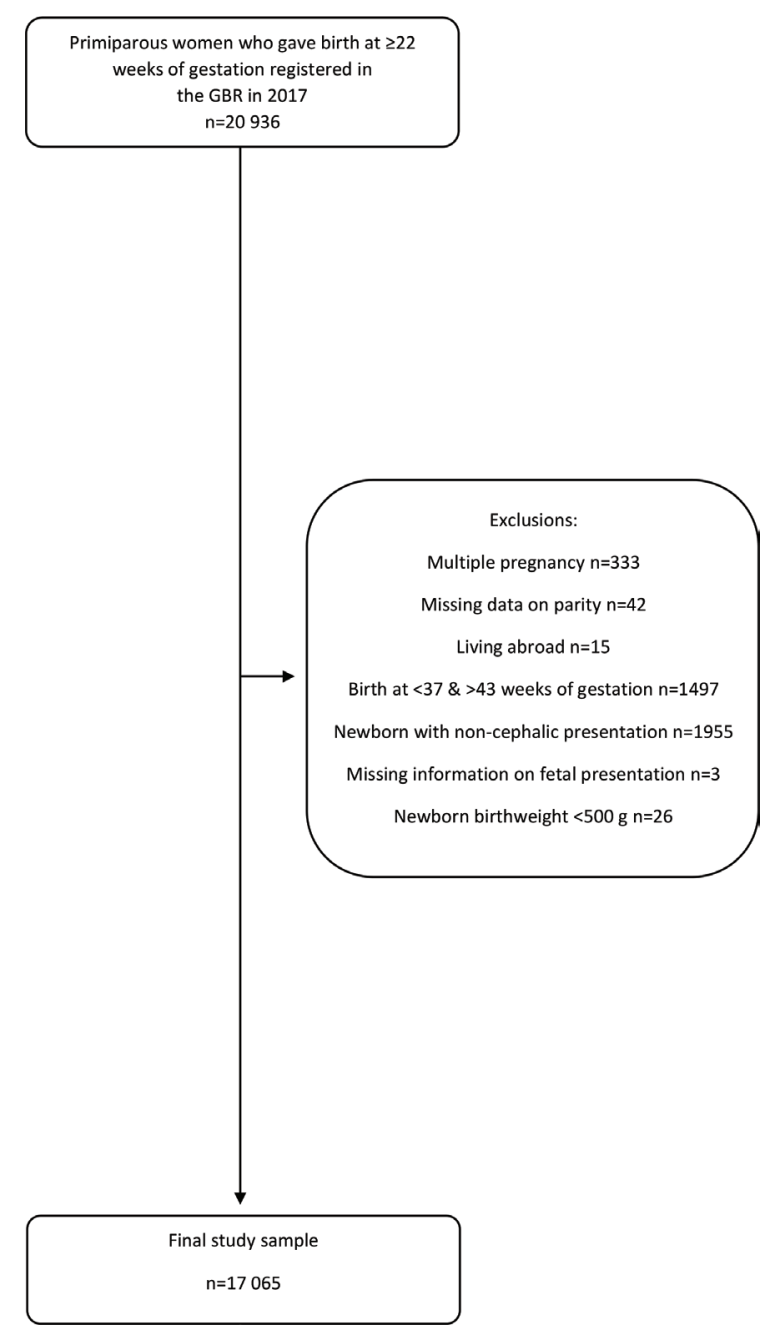

Figure 1 Flow chart of exclusion criteria among primiparous women registered in the GBR in 2017.
The registration forms of GBR were validated through cooperation with the Norwegian Medical Birth Registry. Expert groups performed both forward and backward translations and after 6 months of pilot testing, the system was launched January 1, 2016. Subsequently, the GBR has been checked for internal consistency, content validity and construct validity, in addition to casevalidations through other national electronic health systems. Each birth is validated through the vital registration system, administered by the Ministry of Justice. The proportions of CS are validated through monthly reports from the hospitals to the National Center for Disease Control and Public Health (NCDC).

Overall proportion of CS was analysed as the main outcome. Since the information from the GBR and the official reporting systems are comparable, we are confident that the total proportions of CS from 2017 are reliable. Georgia reported 31.4\% emergency CS $(n=16,329)$ and $13.3 \%$ elective CS $(n=6,899)$ in the same year. The high percentage of emergency CS may indicate misclassifications of CS. Thus, we decided to use CS yes/no as the main outcome.

\subsection{Statistical Analyses}

Descriptive statistics of continuous variables were presented as mean values with Standard Deviations (SDs) for normally distributed continuous variables. For non-normally distributed variables, median and range were provided. Frequencies and percentages were presented for categorical variables.

To identify factors associated with overall CS, we fitted multiple logistic regression models using the purposeful selection method [14]. Variables with a significance level of $p<0.25$ in the univariable models were selected for inclusion in the multivariable analysis.

We applied stepwise elimination, and the full and reduced models were compared using the likelihood ratio test. The final model was selected based on the most reduced model that described the data adequately. Finally, we examined diagnostic plots of the residuals and tested the final model for overall goodness-of-fit using the Hosmer-Lemeshow test. Results are presented as crude and adjusted Odds Ratios (ORs) including 95\% Confidence Intervals (CIs). Statistically significant results were defined as those with $p$-values $<0.05$. The proportion of missing values for earlypregnancy BMI was $25.2 \%$, thus we performed a sensitivity analysis where the regression model was fitted without early-pregnancy BMI (Supplementary Table S1). As there was no substantial difference in effect estimates between the models with and without early-pregnancy BMI, the model including this variable is presented in the results.

Statistical analyses were performed using Stata/SE version 15.0 (Stata Corporation, College Station, TX, USA).

\subsection{Ethical Approval}

The NCDC Institutional Review Board, Georgia - protocol (IRB \# 2017-010 31.03.2017). The GBR released an anonymised study file free of personal identification data, which was used for this study. The Regional Committee for Medical and Health Research Ethics of Northern Norway (REK) approved the use of data from the GBR (2017/404/REK Nord). 


\section{RESULTS}

The overall proportion of CS was $37.1 \%$. Thus, $62.9 \%$ of the women had a vaginal delivery. Mean maternal age was 25.1 years (SD 5.4), and $39.5 \%$ had higher education. $38.0 \%$ of the study population lived in the capital Tbilisi. The median early-pregnancy BMI was $22.0 \mathrm{~kg} / \mathrm{m}^{2}$ (25-75th percentile 20.0-24.8). The percentage of women who attended $\geq 4$ antenatal care visits was $83.9 \%$, and $62.9 \%$ gave birth at 39-40 weeks of gestation. The mean birthweight of newborn was $3325 \mathrm{~g}$ (SD 436) (Table 1). The operative vaginal delivery rate was $1.1 \%$ (data not shown) and $6.0 \%$ of the women had their labor induced.

Characteristics of women with vaginal delivery and CS differed. The percentage of vaginal deliveries decreased with age, from $74.5 \%$ in the age-group $13-19$ years to $30.8 \%$ in women 35 years or older. The proportion of CS increased with increasing level of education, from $26.4 \%$ among women with primary level of education, to $39.7 \%$ among women with higher education. Regional differences were large. The lowest regional proportion was $14.2 \%$, while the highest was $57.4 \%$.

Among women who had a vaginal delivery, $4.8 \%$ had a BMI $>30.0$ $\mathrm{kg} / \mathrm{m}^{2}$, compared to $10.4 \%$ in the CS group. The proportion of women with CS increased with increasing BMI, from $29.4 \%$ among women with a BMI $<18.5 \mathrm{~kg} / \mathrm{m}^{2}$, to $55.9 \%$ among women with a BMI $\geq 30.0 \mathrm{~kg} / \mathrm{m}^{2}$. There was little difference in proportions of CS among women who attended three or less antenatal care visits versus those who attended four or more (36.1\% vs. $37.2 \%)$. Of the $6 \%$ of women who had their labor induced, $40.8 \%$ delivered with a CS. The proportion of deliveries that took place at 37-38 weeks of gestation was $26.8 \%$, and the total proportion of CS in this group was $46.9 \%$. When considering birthweight, the highest proportion of CS (54.7\%) was found among women who gave birth to babies weighing $\geq 4000 \mathrm{~g}$, and the lowest among women who gave birth to babies in the mean weight category of 3000-3499 g (34.3\%) (Table 1).

After multivariable adjustment, women aged $\geq 35$ years had 3.31 (95\% CI; 2.79-3.92) times higher odds of CS, while women aged 30-34 years had 45\% increased odds of CS (OR: 1.45, 95\% CI; 1.28-1.64) compared to women in the 25-29 age group. Women aged 13-19 years had 34\% lower odds of CS (OR: $0.66,95 \% \mathrm{CI}$; 0.57-0.76) compared to the same reference group. Women with primary level of education had lower odds of CS than women with secondary education (OR 0.78, 95\% CI; 0.66-0.92). Further, having a $\mathrm{BMI} \geq 30.0 \mathrm{~kg} / \mathrm{m}^{2}$ was associated with 2.04 -fold $(95 \% \mathrm{CI}$; 1.76-2.36) increased odds of CS compared to women with a BMI of $18.50-24.99 \mathrm{~kg} / \mathrm{m}^{2}$. Women who gave birth at 37-38 weeks of gestation had 78\% higher odds of CS (OR 1.78, 95\% CI; 1.63-1.95) compared to women who gave birth at 39-40 weeks of gestation. Giving birth to a baby weighing $\geq 4000 \mathrm{~g}$ was associated with 2.30 (95\% CI; 1.98-2.66) times higher odds of CS compared to women who gave birth to babies weighing between 3000 and $3499 \mathrm{~g}$ (Table 2).

\section{DISCUSSION}

The total proportion of CS was $37.1 \%$, which is high in primiparous women delivering a single baby in cephalic presentation at term. There were large regional differences in the proportion of CS, ranging from $14.2 \%$ to $57.4 \%$. Maternal age $\geq 35$ years, having obesity (maternal $\mathrm{BMI} \geq 30 \mathrm{~kg} / \mathrm{m}^{2}$ ), delivery at $37-38$ weeks of gestation, and giving birth to a baby weighing $\geq 4000 \mathrm{~g}$ were the main factors associated with CS.

The large regional differences could be an indication of overprovision of CS in certain regions and an under-provision in other regions. It is also possible that more women in some regions travel to larger cities to give birth, as there is a lack of specialists in rural regions, or that there are hospital-dependent differences in economic incentives for interventions.

Advanced maternal age is a risk factor for several morbidities during pregnancy and labor, such as gestational diabetes and fetal distress, which can lead to a higher risk of CS [15]. Age has also been found to be an independent risk factor for CS, regardless of comorbidities [16]. Closely linked with age, high BMI has been reported as an independent risk factor for CS, especially emergency CS [17]. We found that women with a BMI $\geq 30 \mathrm{~kg} / \mathrm{m}^{2}$ had twofold higher odds of CS compared to normal-weight women. This is worrying because the risk of complications during and after surgery, such as wound infection and venous thromboembolism, is considerably higher for women with obesity than normal-weight women [18]. Even though older age and high BMI are frequently cited as strong contributing factors to the general increase in proportions of CS internationally, data from some countries, such as Norway, do not support this statement. In Norway, the proportion of CS has been stable at $17 \%$ for almost 10 years, while the average age of primiparous women and pre-pregnancy BMI has increased [19,20].

Women with primary level of education had 22\% lower odds of CS compared to women who had completed secondary education. Studies evaluating the association between education and CS seem to find opposite results depending on the income level of the country. In low- and middle-income countries, a high level of education is strongly associated with a high proportion of CS [21], while studies performed in high-income countries have found that a lower level of education is associated with CS [22]. Women who gave birth to babies weighing $\geq 4000 \mathrm{~g}$ had 2.30 times higher odds of CS compared to women who birthed average-weight babies. This is to be expected since the national guidelines recommend planned CS for babies with macrosomia, which in Georgia is defined as babies weighing $\geq 4500 \mathrm{~g}$.

Further, primiparous women in Georgia who gave birth at 37-38 weeks of gestation had $78 \%$ higher odds of CS compared to women who gave birth at 39-40 weeks of gestation. The high proportion of deliveries at $37-38$ weeks of gestation $(26.8 \%)$ and the high proportion of CS in this group (46.9\%), are not in line with international standards. In comparison, $16.8-18.5 \%$ of all deliveries in the Nordic countries took place at 37-38 weeks of gestation [23], and the overall proportions of CS in these countries were below $21 \%$. Studies have shown that babies born by CS without a medical indication at 37-38 weeks of gestation have a higher risk of respiratory morbidity and transfer to neonatal intensive care unit compared to babies born at 39-40 weeks of gestation [24]. Thus, in order to meet the goal and reduce the proportion of CS, a contributing step would be for the health authorities to target the high rate of CS that occur at 37-38 weeks of gestation and issue guidelines to avoid unnecessary interventions without a valid medical indication.

In line with our findings, previous studies from countries like Canada (proportion of CS 26.3\%) [25], Bangladesh (23.0\%) [26] and Mozambique (2.3\%) [27] have reported large regional differences in proportions of CS and associations between factors 
Table 1 Characteristics of primiparous women and their newborn, stratified by mode of delivery, $n=17,065$

\begin{tabular}{|c|c|c|c|}
\hline Characteristics & Vaginal delivery & Cesarean section & Total \\
\hline Total number of women, $n(\%)$ & $10,741(62.9)$ & $6324(37.1)$ & $17,065(100)$ \\
\hline Maternal age, years, mean (SD) & $24.2(4.7)$ & $26.6(6.0)$ & $25.1(5.4)$ \\
\hline Maternal age (years, \%) & & & $n(\%)$ \\
\hline $13-19$ & 74.5 & 25.5 & $2303(13.5)$ \\
\hline $20-24$ & 67.8 & 32.2 & $6440(37.7)$ \\
\hline $25-29$ & 63.3 & 36.7 & $5057(29.6)$ \\
\hline $30-34$ & 51.6 & 48.4 & $2156(12.6)$ \\
\hline$\geq 35$ & 30.8 & 69.2 & $1109(6.5)$ \\
\hline Education $(\%)^{\dagger}$ & & & $n(\%)$ \\
\hline Primary & 73.6 & 26.4 & $1374(8.1)$ \\
\hline Secondary & 63.1 & 36.9 & $7641(44.8)$ \\
\hline Higher education & 60.3 & 39.7 & $6732(39.5)$ \\
\hline Unknown & 64.3 & 35.7 & $1317(7.7)$ \\
\hline Geographical region of residence $(\%)^{\ddagger}$ & & & $n(\%)$ \\
\hline Tbilisi & 65.4 & 34.6 & $6421(38.0)$ \\
\hline Imereti & 57.3 & 42.7 & $1997(11.8)$ \\
\hline Adjara & 52.6 & 47.4 & $1991(11.8)$ \\
\hline Kvemo Kartli & 72.0 & 28.0 & $1893(11.2)$ \\
\hline Samegrelo and Zemo Svaneti & 45.6 & 54.4 & $1156(6.8)$ \\
\hline Kakheti & 64.5 & 35.5 & $1040(6.2)$ \\
\hline Shida Kartli & 66.1 & 33.9 & $948(5.6)$ \\
\hline Samtskhe-Javakheti & 85.8 & 14.2 & $586(3.5)$ \\
\hline Guria & 67.2 & 32.8 & $363(2.2)$ \\
\hline Mtskheta-Mtianeti & 68.7 & 31.3 & $297(1.8)$ \\
\hline Abkhazia & 42.7 & 57.4 & $136(0.8)$ \\
\hline Racha-Lechkhumi and Kvemo Svaneti & 60.8 & 39.2 & $74(0.4)$ \\
\hline \multicolumn{4}{|c|}{ Body mass index $\left(\mathrm{kg} / \mathrm{m}^{2}\right)$, median $(25-75$ th percentile) } \\
\hline Based on $12,597 / 17,065$ & $21.6(19.8-24.1)$ & $22.9(20.4-26.1)$ & $22.0(20.0-24.8)$ \\
\hline Body mass index $\left(\mathrm{kg} / \mathrm{m}^{2}, \%\right)^{\varsigma}$ & & & $n(\%)$ \\
\hline$<18.5$ & 70.6 & 29.4 & $1268(10.1)$ \\
\hline $18.50-24.99$ & 66.2 & 33.8 & $8347(66.3)$ \\
\hline $25.00-29.99$ & 54.1 & 45.9 & $2114(16.8)$ \\
\hline$\geq 30.00$ & 44.1 & 55.9 & $868(6.9)$ \\
\hline \multicolumn{4}{|l|}{ Number of antenatal care visits attended (\%) } \\
\hline $0-3$ & 63.9 & 36.1 & $2748(16.1)$ \\
\hline$\geq 4$ & 62.8 & 37.2 & $14,317(83.9)$ \\
\hline \multicolumn{4}{|l|}{ Induction of labor } \\
\hline Yes & 59.2 & 40.8 & $1031(6.0)$ \\
\hline No & 63.2 & 36.8 & $16,034(94.0)$ \\
\hline Weeks of gestation (\%) & & & $n(\%)$ \\
\hline $37-38$ & 53.1 & 46.9 & $4580(26.8)$ \\
\hline $39-40$ & 67.1 & 32.9 & $10,737(62.9)$ \\
\hline $41-43$ & 63.3 & 36.7 & $1748(10.2)$ \\
\hline Birthweight (g), mean (SD) & $3298(408)$ & $3370(478)$ & $3325(436)$ \\
\hline Birthweight (g, \%) & & & $n(\%)$ \\
\hline$<2500$ & 56.8 & 43.2 & $333(2.0)$ \\
\hline $2500-2999$ & 65.5 & 34.5 & $2983(17.5)$ \\
\hline $3000-3499$ & 65.8 & 34.3 & $7658(44.9)$ \\
\hline $3500-3999$ & 61.8 & 38.2 & $4862(28.5)$ \\
\hline$\geq 4000$ & 45.3 & 54.7 & $1229(7.2)$ \\
\hline
\end{tabular}

${ }^{\dagger}$ One missing for education. ${ }^{\ddagger} 163$ missing for geographical region of residence. ${ }^{\S} 4437$ missing for body mass index, 31 excluded due to out of range. $n$, number; SD, standard deviation.

such as high birthweight, advanced maternal age and/or obesity and CS. Our study found that mean maternal age and median BMI of Georgian women, and the mean birthweight of Georgian babies, were similar to those in countries with a much lower proportion of CS. Thus, our results suggest that these factors are not the main drivers of the high proportion of CS in Georgia. Instead, there may be organisational and financial aspects of the Georgian maternal health system that could be evaluated. A high national proportion of CS may be considered a symptom of overmedicalisation of maternal care. A system where women are selected to either midwifery or specialist care depending on their risk profile should be encouraged. Although such as system has never been initiated in Georgia, steps could be taken to make midwives the main care givers in antenatal and intrapartum care for low-risk women. Indeed, studies have shown that low-risk women cared for by midwives experience fewer interventions 
Table 2 Crude and multivariable adjusted odds ratios (OR) and 95\% confidence intervals (CI) for cesarean sections by characteristics among primiparous women, $n=17,065$

\begin{tabular}{|c|c|c|}
\hline & $\begin{array}{c}\text { Univariable } \\
\text { analysis }\end{array}$ & $\begin{array}{l}\text { Multivariable } \\
\text { analysis }\end{array}$ \\
\hline & OR $(95 \% \mathrm{CI})$ & OR $(95 \% \mathrm{CI})^{*}$ \\
\hline \multicolumn{3}{|l|}{ Maternal age (years) } \\
\hline $13-19$ & $0.59[0.53-0.66]$ & $0.66[0.57-0.76]$ \\
\hline $20-24$ & $0.82[0.76-0.89]$ & $0.85[0.77-0.93]$ \\
\hline $25-29$ & Reference & Reference \\
\hline $30-34$ & 1.62 [1.46-1.79] & $1.45[1.28-1.64]$ \\
\hline$\geq 35$ & $3.87[3.37-4.45]$ & $3.31[2.79-3.92]$ \\
\hline \multicolumn{3}{|l|}{ Education level } \\
\hline Primary & $0.62[0.54-0.70]$ & $0.78[0.66-0.92]$ \\
\hline Secondary & Reference & Reference \\
\hline Higher education & $1.13[1.05-1.21]$ & $0.90[0.83-0.99]$ \\
\hline Unknown & $0.95[0.84-1.07]$ & $0.95[0.81-1.12]$ \\
\hline \multicolumn{3}{|c|}{ Body mass index $\left(\mathrm{kg} / \mathrm{m}^{2}\right)^{\dagger}$} \\
\hline$>18.5$ & $0.82[0.72-0.93]$ & $0.88[0.77-1.00]$ \\
\hline $18.50-24.99$ & Reference & Reference \\
\hline $25.00-29.99$ & $1.66[1.51-1.83]$ & $1.46[1.32-1.61]$ \\
\hline$\geq 30.00$ & $2.48[2.15-2.86]$ & $2.04[1.76-2.36]$ \\
\hline \multicolumn{3}{|l|}{ Weeks of gestation } \\
\hline $37-38$ & 1.80 [1.68-1.93] & $1.78[1.63-1.95]$ \\
\hline $39-40$ & Reference & Reference \\
\hline $41-43$ & $1.18[1.06-1.31]$ & $1.12[0.98-1.27]$ \\
\hline \multicolumn{3}{|l|}{ Birthweight, g } \\
\hline$<2500$ & $1.46[1.17-1.83]$ & $1.25[0.95-1.65]$ \\
\hline $2500-2999$ & $1.01[0.93-1.11]$ & $0.92[0.82-1.03]$ \\
\hline $3000-3499$ & Reference & Reference \\
\hline $3500-3999$ & $1.19[1.10-1.28]$ & $1.25[1.14-1.37]$ \\
\hline$\geq 4000$ & $2.32[2.05-2.62]$ & $2.30[1.98-2.66]$ \\
\hline
\end{tabular}

${ }^{\dagger} 4437$ missing for BMI, 31 excluded due to out of range. "Adjusted for all variables in the table. Antenatal care visits were not significant in the univariate analysis and therefore not included.

than women cared for by obstetricians $[10,28]$. The Nordic countries are examples of systems where midwives are the main care givers during pregnancy and labor, and where the percentage of CS have been stable between $15 \%$ and $21 \%$ for the past decade. The health system in Georgia has in the past 20 years seen a large increase in the number of physicians entering the labor market, while the number of midwives has declined.

Another aspect is the complete privatisation of health care in Georgia, where financial incentives for doctors may be a contributing factor to the increasing proportion of CS [7,29]. Georgia introduced universal health care in 2013 , where hospitals are reimbursed from the state for treatment and procedures pertaining to each patient, and CS have a higher reimbursement than vaginal delivery. It has been well documented from other countries that CS rates in private hospitals are higher compared to public hospitals, independent of case-mix [21].

In contrast to Europe where the total induction rate in 2010 varied from $8.3 \%$ to $28.0 \%$ [30], and the median of total operative vaginal deliveries in 2015 was $7.2 \%$ [31], we found among primiparous women in Georgia a low induction rate (6.0\%), and a $40.8 \%$ proportion of CS in this subset of women. Better selection strategies for high risk pregnancies, followed by more inductions for conditions that do not require immediate delivery could reduce the CS rates [12]. Increasing knowledge and training of how to perform operative vaginal deliveries could lead to less emergency CS.

Georgia reported that, $31.4 \%$ of women who gave birth in 2017 had an emergency CS, in the study sample of nulliparous women the percentage was 23.6. These numbers are markedly higher than other European countries listed in the Peristat report from 2015, where the total percentage of emergency CS ranged from $7.6 \%$ to $17.6 \%$, except for Romania [31]. The high rate and possible misclassification of emergency CS should be of interest to Georgian health authorities and other countries that intend to reduce their CS rates, since Georgia have a national goal to reduce the overall CS rate from $43.5 \%$ (2016) to $31 \%$ in 2020 and further reductions by 2030 . A strategy of placing restrictions on the number of CS may not yield the desired result if it leads to elective CS being "converted" to emergency CS to avoid possible economic sanctions. Further investigations are needed to uncover for what reasons misclassifications are occurring.

\subsection{Strengths and Limitations}

A strength of the study is that national numbers on CS based on a medical birth registry are presented for the first time. The GBR had $99.5 \%$ coverage in 2017 and it is estimated that $99 \%$ of women in Georgia give birth in maternity wards [3]. Thus, the results should represent the Georgian population.

It is a limitation that we could not differentiate between emergency and elective CS. By keeping CS as one variable, we potentially lose valuable information on factors that differentiate the two groups of women who had an elective or an emergency CS. The youngest age group could not be further divided into $<15$ years and 15-19 years due to a very low number of women in the 13-14 age group. We were concerned that the lowest age group would be too small to use statistically. In addition, after stratification such small groups are prone to the possibility of personal identification, which we wanted to avoid to be in compliance with the General Data Protection Regulation [32]. We risk losing information pertaining specifically to the youngest women in the sample. It was, however, important to include them to obtain the whole picture.

\section{CONCLUSION}

Maternal age above 30 years, having obesity, and high birthweight were all positively associated with CS among primiparous women in Georgia. An important finding is the high proportion of CS among early term deliveries, which may support that organisational matters of maternity care and economic incentives in a privatized healthcare system, may be areas for further research of attempts to prevent unnecessary CS without compromising maternal and newborn morbidity. There is a need to investigate the high proportion of CS classified as emergency procedures since strategies to reduce the CS rates will depend on the type of CS performed.

\section{CONFLICTS OF INTEREST}

Tamara Ugulava works for UNICEF, which was one of the major financial contributors to the establishment of the Georgian Birth Registry. The remaining authors have no conflicts of interest to disclose. 


\section{AUTHORS' CONTRIBUTION}

IHN was involved in study design, data analysis, data interpretation, in the writing and drafting of the article, figures, and tables. CR was involved in study design, data cleaning, data analysis, data interpretation, and writing of the article. FES was involved with study design, data interpretation, and writing of the article. EB was involved in data interpretation and writing of the article. TU was involved in revising the article. EEA was involved in study design, data interpretation, and writing of the article. All authors have reviewed and approved the final manuscript.

\section{FUNDING}

The first author received a $\mathrm{PhD}$ grant from UiT The Arctic University of Norway to carry out the study.

\section{ACKNOWLEDGMENTS}

The authors would like to thank the staff at the Georgian Birth Registry office in Tbilisi and PhD-candidate Tinatin Manjavidze, in addition to Mary Taylor and Nils Daulaire for reading and commenting on drafts of the manuscript.

\section{SUPPLEMENTARY MATERIAL}

Supplementary data related to this article can be found at https:// doi.org/10.2991/jegh.k.200813.001.

\section{REFERENCES}

[1] Keag OE, Norman JE, Stock SJ. Long-term risks and benefits associated with cesarean delivery for mother, baby, and subsequent pregnancies: systematic review and meta-analysis. PLoS Med 2018;15;e1002494.

[2] Katikireddi SV, Gorman DR, Leyland AH. A comparison of trends in caesarean section rates in former communist (transition) countries and other European countries. Eur J Public Health 2013;23;381-3.

[3] Anda EE, Nedberg IH, Rylander C, Gamkrelidze A, Turdziladze A, Skjeldestad FE, et al. Implementing a birth registry in a developing country - experiences from Georgia. Tidsskr Nor Laegeforen 2017;138;7-12 [Article in En, Norwegian].

[4] Ministry of Health. Universal healthcare state programs Ordinance N36. Tbilisi, Georgia: Government of Georgia; 2013.

[5] Yisma E, Smithers LG, Lynch JW, Mol BW. Cesarean section in Ethiopia: prevalence and sociodemographic characteristics. J Matern Fetal Neonatal Med 2019;32;1130-5.

[6] Begum T, Rahman A, Nababan H, Hoque DME, Khan AF, Ali T, et al. Indications and determinants of caesarean section delivery: evidence from a population-based study in Matlab, Bangladesh. PLoS One 2017;12;e0188074.

[7] Miller S, Abalos E, Chamillard M, Ciapponi A, Colaci D, Comandé $\mathrm{D}$, et al. Beyond too little, too late and too much, too soon: a pathway towards evidence-based, respectful maternity care worldwide. Lancet 2016;388;2176-92.
[8] Mossialos E, Allin S, Karras K, Davaki K. An investigation of Caesarean sections in three Greek hospitals: the impact of financial incentives and convenience. Eur J Public Health 2005;15;288-95.

[9] Zwecker P, Azoulay L, Abenhaim HA. Effect of fear of litigation on obstetric care: a nationwide analysis on obstetric practice. Am J Perinatol 2011;28;277-84.

[10] Sandall J, Soltani H, Gates S, Shennan A, Devane D. Midwife-led continuity models versus other models of care for childbearing women. Cochrane Database Syst Rev 2016;4;CD004667.

[11] Hoxha I, Syrogiannouli L, Luta X, Tal K, Goodman DC, da Costa $\mathrm{BR}$, et al. Caesarean sections and for-profit status of hospitals: systematic review and meta-analysis. BMJ Open 2017;7;e013670.

[12] Spong CY, Berghella V, Wenstrom KD, Mercer BM, Saade GR. Preventing the first cesarean delivery: summary of a joint Eunice Kennedy Shriver National Institute of Child Health and Human Development, Society for Maternal-Fetal Medicine, and American College of Obstetricians and Gynecologists Workshop. Obstet Gynecol 2012;120;1181-93.

[13] WHO Reproductive Health Library. WHO recommendation on group antenatal care. Geneva, Switzerland: World Health Organization; 2016. Available from: https://extranet.who.int/rhl/ topics/improving-health-system-performance/who-recommendation-antenatal-care-contact-schedules (accessed June 8, 2020).

[14] Hosmer DW, Lemeshow S. Logistic regression. In: Veierød MB, Lydersen S, Laake P, editors. Medical statistics in clinical and epidemiological research. Oslo: Gyldendal Akademisk; 2012, pp. 90-126.

[15] Ludford I, Scheil W, Tucker G, Grivell R. Pregnancy outcomes for nulliparous women of advanced maternal age in South Australia, 1998-2008. Aust N Z J Obstet Gynaecol 2012;52;235-41.

[16] Bayrampour H, Heaman M. Advanced maternal age and the risk of cesarean birth: a systematic review. Birth 2010;37;219-26.

[17] Rahman MM, Abe SK, Kanda M, Narita S, Rahman MS, Bilano V, et al. Maternal body mass index and risk of birth and maternal health outcomes in low- and middle-income countries: a systematic review and meta-analysis. Obes Rev 2015;16;758-70.

[18] Gilead R, Yaniv Salem S, Sergienko R, Sheiner E. Maternal "isolated" obesity and obstetric complications. J Matern Fetal Neonatal Med 2012;25;2579-82.

[19] Ebbing M. Fødsler i Norge 1967-2016 - noen nøkkeltall. [Births in Norway 1967-2016 - some key figures]. Norsk Epidemiologi 2017;27;9-12.

[20] Meyer HE, Bøhler L, Vollrath M. Overweight and obesity in Norway. Oslo: Norwegian Public Health Institute; 2017. Available from: https://www.fhi.no/en/op/hin/lifestyle/overweight-and-obesity-innorway---/\#about-the-article (accessed October 4, 2019).

[21] Boerma T, Ronsmans C, Melesse DY, Barros AJD, Barros FC, Juan L, et al. Global epidemiology of use of and disparities in caesarean sections. Lancet 2018;392;1341-8.

[22] Cammu H, Martens G, Keirse MJNC. Mothers' level of education and childbirth interventions: a population-based study in Flanders, Northern Belgium. Birth 2011;38;191-9.

[23] Richards JL, Kramer MS, Deb-Rinker P, Rouleau J, Mortensen L, Gissler M, et al. Temporal trends in late preterm and early term birth rates in 6 high-income countries in North America and Europe and association with clinician-initiated obstetric interventions. JAMA 2016;316;410-19.

[24] do Carmo Leal M, Esteves-Pereira AP, Nakamura-Pereira M, Domingues RMSM, Dias MAB, Moreira ME, et al. Burden of 
early-term birth on adverse infant outcomes: a population-based cohort study in Brazil. BMJ Open 2017;7;e017789.

[25] Hanley GE, Janssen PA, Greyson D. Regional variation in the cesarean delivery and assisted vaginal delivery rates. Obstet Gynecol 2010;115;1201-8.

[26] Khan MN, Islam MM, Shariff AA, Alam MM, Rahman MM. Socio-demographic predictors and average annual rates of caesarean section in Bangladesh between 2004 and 2014. PLoS One 2017; 12; 0177579 .

[27] Long Q, Kempas T, Madede T, Klemetti R, Hemminki E. Caesarean section rates in Mozambique. BMC Pregnancy Childbirth 2015;15;253.

[28] Brocklehurst P, Hardy P, Hollowell J, Linsell L, Macfarlane A, McCourt C, et al. Perinatal and maternal outcomes by planned place of birth for healthy women with low risk pregnancies: the Birthplace in England national prospective cohort study. BMJ 2011;343; d7400.
[29] Singh P, Hashmi G, Swain PK. High prevalence of cesarean section births in private sector health facilities- analysis of district level household survey-4 (DLHS-4) of India. BMC Public Health 2018;18;613.

[30] Euro-Peristat Project. European Perinatal Health Report. Health and care of pregnant women and babies in Europe in 2010. 2013. Available from: https://www.europeristat.com/images/doc/ EPHR2010_w_disclaimer.pdf (accessed November 20, 2019).

[31] Euro-Peristat Project. European Perinatal Health Report. Core indicators of the health and care of pregnant women and babies in Europe in 2015. 2018. Available from: https://www.europeristat.com/images/EPHR2015_web_hyperlinked_Euro-Peristat. pdf (accessed May 14, 2019).

[32] General Data Protection Regulation. Art. 5 GDPR - Principles relating to processing of personal data. 2016. Available from: https://eur-lex.europa.eu/legal-content/EN/TXT/HTML/ ?uri=CELEX:32016R0679\&rid=3\#d1e40-1-1. 